\title{
Endovascular abdominal aortic aneurysm repair: type 2 endoleaks and risk of rupture
}

\author{
Correção endovascular do aneurisma da aorta abdominal: \\ vazamento tipo 2 e o risco de rotura
}

Fausto Miranda Jr. ${ }^{1}$

The advent of endovascular aneurysm repair (EVAR) for aneurysms of the abdominal aorta (AAA) has brought with it a novel morbidity. The complication is known as endoleakage, in which escaped blood causes pressurization of the aneurysm sac. This means that a risk remains of a much dreaded ruptured aneurysm, although the degree of risk is not uniform across all different types of endoleak. ${ }^{1}$ It has been recommended that types 1 and 3 endoleaks should be repaired promptly; but there is still an ongoing debate on whether the ideal management for type 2 endoleaks is intervention or clinical follow-up.

This debate is not a recent phenomenon. At one conference of specialists on the subject, it was concluded that type 2 endoleaks can occur in 10 to $25 \%$ of endovascular repairs of abdominal aortic aneurysms. In from 30 to $100 \%$ of these cases, the leak will occlude spontaneously, without adversely affecting clinical progress. However, when there is growth of the aneurysm after EVAR, surgical or endovascular intervention is mandatory. ${ }^{2}$

A systematic review that selected 61 out of 606 studies assessed the efficacy and safety of 19,804 cases of elective endovascular repair for aneurysms of the infrarenal aorta. Type 2 endoleaks were the most common, occurring in $14 \%$ of cases within 1 month and decreasing spontaneously to $10.3 \%$ within 12 months. $^{3}$

A retrospective analysis of the Cleveland Clinic's experience over an 8-year period from October 1999 to December 2007 showed that there were just nine $(0.52 \%)$ cases of type 2 endoleak after a total of 1,606 EVARs. ${ }^{4}$ During our experience treating 105 consecutive AAA cases using a single type of endoprosthesis from March 1997 to July 2003, we have observed four (3.8\%) cases of type 2 endoleak. $^{5}$

Analysis of a series of 873 patients who underwent EVAR for AAA identified 164 (18.9\%) cases of type 2 endoleak. Of these, 131 cases $(79.9 \%)$ had resolved fully within 6 months, and no adverse events had occurred during the same time frame. Among those that remained beyond 6 months, there were four cases of aneurysm rupture after a mean interval of 31.6 months, suggesting either that monitoring should be more intensive or that more aggressive interventions should be employed. ${ }^{6}$

Computed tomography was used to investigate a sample of 486 consecutive EVAR-AAA patients for the presence of type 2 endoleaks and growth of the aneurysm sac exceeding $5 \mathrm{~mm}$. Type 2 endoleaks were detected in $90(18.5 \%)$ of these patients. Over a mean follow-up of $21.7 \pm 16$ months, just 35 (7.2\%) patients had type 2 endoleaks persisting for more than 6 months. Aneurysm sac growth was observed in five patients, accounting for $1 \%$ of the whole series. After treatment, there was no relapse to renewed aneurysm growth over 18.2 \pm 8 months' follow-up. None of the aneurysms ruptured during follow-up of type 2 endoleaks, irrespective of whether treated or not.?

Preoperative EVAR computed tomography findings of circumferential mural thrombus appear to be a protective factor against type 2 endoleaks. ${ }^{8}$ Along the same lines, a retrospective study of preoperative tomographs from 326 patients analyzed diameter of aneurysm, presence of mural thrombus and patency of the inferior mesenteric artery and the lumbar arteries. Univariate analysis showed that patency of all lumbar arteries was a significant predictor of type 2 endoleak. On the other hand, the multivariate analysis showed that occlusion of the inferior mesenteric artery or occlusion of the pair of lumbar arteries at the L3 or L4 level is an independent protective factor against type 2 endoleaks. ${ }^{9}$

A 24-month follow-up study of 108 patients who had undergone embolization of the inferior mesenteric artery before EVAR for AAA reported reductions in the rate of aneurysm sac growth and in type 2 endoleaks. ${ }^{10}$ One argument against routine preoperative embolization of the inferior mesenteric artery is the risk of intestinal ischemia. The recommendation is that only the trunk of the inferior mesenteric artery should be embolized, 
leaving the left colic artery and the superior rectal artery untouched..$^{11}$ In turn, preoperative embolization of the lumbar arteries tends to be a more protracted and technically more difficult procedure with a higher rate of technical failures and, for these reasons, the majority of specialists do not attempt this intervention. ${ }^{12}$

Doppler ultrasonography assessment of the flow velocity spectrum can be predictive of spontaneous occlusion of type 2 endoleaks. A follow-up study of 265 patients who underwent EVAR for AAA identified 14 patients whose type 2 endoleaks had sealed with no intervention within 6 months. A further 16 patients had endoleaks that persisted beyond 6 months. Flow velocities were lower in the group with endoleaks that sealed in less than 6 months $(75.5 \pm 78.8 \mathrm{~cm} / \mathrm{s}$ vs. $138 \pm 36.2 \mathrm{~cm} / \mathrm{s} ; \mathrm{p}<0.01)$. Patients with endoleaks that sealed and low flow velocities $(<100 \mathrm{~cm} / \mathrm{s})$ had a lower proportion of patent inferior mesenteric arteries $(43 \%$ vs. $81 \%$; $\mathrm{p}<0.01)$, a smaller diameter inferior mesenteric artery $(5.6 \pm 1.8 \mathrm{~mm}$ vs. $7.2 \pm 1.3 \mathrm{~mm} ; \mathrm{p}<0.01)$ and a lower number of paired lumbar arteries $(1.3 \pm 0.8 \mathrm{vs}$. $2.4 \pm 0.6 ; p<0.0001)$, when compared with the group with persistent endoleaks and intra-sac velocities higher than $100 \mathrm{~cm} / \mathrm{s}$. These data suggest that higher velocity type 2 endoleaks are related to the higher numbers and larger diameters of branches found during preoperative assessments. ${ }^{13}$

A study that analyzed a series of 195 patients for the presence of factors predictive of the occurrence of type 2 endoleaks using computed tomography observed type 2 endoleaks in $28(13.4 \%)$ patients. In ten of these patients there were a mean of 4.3 patent lumbar arteries, with diameters smaller than $2 \mathrm{~mm}$ (mean of $1.5 \mathrm{~mm}$ ). In the other 18 patients, the mean diameter of the lumbar arteries was $2.7 \mathrm{~mm}$. No significant correlation was observed between diameter or patency of the inferior mesenteric artery and development of type 2 endoleak. However, the presence of four patent lumbar arteries $(\mathrm{p}<0.001)$ or at least one patent internal iliac artery $(p<0.001)$ were predictive factors. The same was true of at least one patent lumbar artery with a diameter greater than 2 $\mathrm{mm}(\mathrm{p}<0.001) .{ }^{14}$

With regard to the debate over whether to intervene or monitor in type 2 endoleak cases, we have adopted the following conduct for monitoring patients after EVAR for AAA: a computed tomography examination is conducted within 1 month of the procedure and, depending on the result, an ultrasonography examination of the aorta and iliac arteries will be conducted every 6 or 12 months, by a laboratory affiliated to our service. These control examinations are intended to monitor the aneurysm diameter and detect any endoleaks. In cases of type 2 endoleaks, depending on ultrasonographic findings, examinations will be repeated at 2 or 3 -month intervals in order to detect any growth in the aneurysm sac.

\section{REFERENCES}

1. Buth J, Harris PL, van Marrewijk C. Causes and outcomes of open conversion and aneurysm rupture after endovascular abdomina aortic aneurysm repair: can type II endoleaks be dangerous? J Am Coll Surg. 2002;194(1, Suppl):S98-102. http://dx.doi.org/10.1016/ S1072-7515(01)01128-0. PMid:11800362

2. Veith FJ, Baum RA, Ohki T, et al. Nature and significance of endoleaks and endotension: summary of opinions expressed at an international conference. J Vasc Surg. 2002;35(5):1029-35. http:// dx.doi.org/10.1067/mva.2002.123095. PMid:12021724

3. Drury D, Michaels JA, Jones L, Ayiku L. Systematic review of recent evidence for the safety and efficacy of elective endovascular repair in the management of infrarenal abdominal aortic aneurysm. $\mathrm{Br}$ J Surg. 2005;92(8):937-46. http://dx.doi.org/10.1002/bjs.5123. PMid:16034817

4. Kelso RL, Lyden SP, Butler B, Greenberg RK, Eagleton MJ, Clair DG Late conversion of aortic stent grafts. J Vasc Surg. 2009;49(3):58995. http://dx.doi.org/10.1016/j.jvs.2008.10.020. PMid:19135829

5. Sampaio AM. Endovascular treatment of infrarenal abdominal aorta aneurysm [tese]. São Paulo: Escola Paulista de Medicina; 2005.

6. Jones JE, Atkins MD, Brewster DC, et al. Persistent type 2 endoleak after endovascular repair of abdominal aortic aneurysm is associated with adverse late outcomes. J Vasc Surg. 2007;46(1):1-8 http://dx.doi.org/10.1016/j.jvs.2007.02.073. PMid:17543489

7. Steinmetz E, Rubin BG, Sanchez LA, et al. Type II endoleak after endovascular abdominal aortic aneurysm repair: a conservative approach with selective intervention is safe and cost-effective. J Vasc Surg. 2004;39(2):306-13. http://dx.doi.org/10.1016/j. jvs.2003.10.026. PMid:14743129

8. Brountzos E, Karagiannis G, Panagiotou I, Tzavara C, Efstathopoulos E, Kelekis N. Risk factors for the development of persistent type II endoleaks after endovascular repair of infrarenal abdominal aortic aneurysms. Diagn Interv Radiol. 2012;18(3):307-13. PMid:21986961.

9. Ward TJ, Cohen S, Patel RS, et al. Anatomic risk factors for type-2 endoleak following EVAR: a retrospective review of preoperative CT angiography in 326 patients. Cardiovasc Intervent Radiol. 2014;37(2):324-8. http://dx.doi.org/10.1007/s00270-013-0646-7. PMid:23703668

10. Ward TJ, Cohen S, Fischman AM, et al. Preoperative inferior mesenteric artery embolization before endovascular aneurysm repair: decreased incidence of type II endoleak and aneurysm sac enlargement with 24-month follow-up. J Vasc Interv Radiol. 2013;24(1):49-55. http://dx.doi.org/10.1016/j.jvir.2012.09.022. PMid:23273697

11. Müller-Wille R, Uller W, Gößmann $H$, et al. Inferior mesenteric artery embolization before endovascular aortic aneurysm repair using amplatzer vascular plug type 4. Cardiovasc Intervent Radiol. 2014;37(4):928-34. http://dx.doi.org/10.1007/s00270-013-0762-4. PMid:24170169

12. Bonvini R, Alerci M, Antonucci F, et al. Preoperative embolization of collateral side branches: a valid means to reduce type II endoleaks after endovascular AAA repair. J Endovasc Ther. 2003;10(2):227-32. 
http://dx.doi.org/10.1583/1545-1550(2003)010<0227:PEOCSB> 2.0.CO;2. PMid:12877603

13. Arko FR, Filis KA, Siedel SA, et al. Intrasac flow velocities predict sealing of type II endoleaks after endovascular abdominal aortic aneurysm repair. J Vasc Surg. 2003;37(1):8-15. http://dx.doi. org/10.1067/mva.2003.55. PMid:12514572

14. Marchiori A, von Ristow A, Guimaraes M, Schönholz C, Uflacker R. Predictive factors for the development of type II endoleaks. J Endovasc Ther. 2011;18(3):299-305. http://dx.doi.org/10.1583/103116.1. PMid:21679064
Correspondence Fausto Miranda Jr. Rua Estela, 515, bloco G, cj 81 - Paraiso CEP 04011-002 - São Paulo (SP), Brazil E-mail:fmiranda@apm.org.br

Author information FMJ - Full professor of Vascular and Endovascular Surgery at Escola Paulista de Medicina da Universidade Federal de São Paulo (UNIFESP). 